\title{
Estimates and Determinants of Psychological Problems of Pregnant Women during COVID-19 Epidemic in South Africa
}

\author{
A. M. Hoque, M. Hoque, M. E. Hoque, and G. Van Hal
}

\section{ABSTRACT}

The COVID-19 epidemic has impacted significantly on the general population including pregnant women. The psychological impact of COVID-19 among vulnerable population like pregnant women is yet to be estimated. Therefore, the objective of this study was to estimate the prevalence and factors associated with anxiety, depression, and overall psychological problems. A questionnaire-based cross-sectional study was conducted among black pregnant women attending a Primary Health Care facility in South Africa. Logistic regression analysis was performed to determine the significant factors for psychological problems. A total of 346 pregnant women participated in this study. The rates of anxiety, depression and overall psychological problems were $35.7 \%, 38.2 \%$ and $34.3 \%$ respectively. Gestational age between 14-26 weeks were $60 \%(\mathrm{OR}=.397$, $\mathrm{p}<0.05)$, part-time employment $53 \%(\mathrm{OR}=0.47, \mathrm{p}<0.05)$ and pregnant women having adequate funding for monthly expenses were $62 \%$ less likely $(\mathrm{OR}=0.381, \mathrm{p}<0.05)$ to have anxiety problems. Married women were 2.5 times more likely $(\mathrm{OR}=2.54, \mathrm{p}<0.05)$ and women living together or widowed were 2.9 times more likely $(O R=2.91, p<0.05)$ to have anxiety. Pregnant women aged between 20-29 years were nine times $(O R=9.03$, $\mathrm{p}=0.016)$, women aged 30 to 39 years were 6.3 times $(\mathrm{OR}=6.3, \mathrm{p}=0.032)$ more likely to have depression. Parity one $91 \%(\mathrm{OR}=\mathbf{0 . 0 9 4}, \mathrm{p}=\mathbf{0 . 0 0 7})$, parity two $86 \%(\mathrm{OR}=.143, \mathrm{p}=\mathbf{0 . 0 2 7})$ and part-time employment $65 \%$ $(\mathrm{OR}=0.354, \mathrm{p}=\mathbf{0 . 0 0 2})$ were less likely to have depression. Comparing with women aged $>39$ years, women who were between 20-29 years were 28 times $(O R=27.8, p<0.01)$ and women aged between $30-39$ years were nine times more likely to have overall psychological problems. Respondents with parity one was $83 \%(\mathrm{OR}=0.17, \mathrm{p}<0.05)$ less likely to have psychological problems when compared with other parity groups and women having adequate funding were $65 \%$ less likely $(O R=0.35, p<0.05)$ to have overall psychological problems than those did not have adequate funding. Higher rates of anxiety, depression and overall psychological problems are found among black pregnant women. It is therefore imperative that appropriate and timely mental health care supports are provided to reduce adverse health outcomes.

Keywords: Anxiety, Depression, Psychological impact, Prevalence, Risk factors.

\section{INTRODUCTION}

Since coronavirus disease of 2019 known as COVID-19 has identified and emerged globally from Wuhan, China, in December 2019 it is the largest pandemic humanity is dealing with [1]. The COVID-19 outbreak has impacted significantly on the general population of South Africa (SA) as there are 589886 cases (58\% being female) and 11982 deaths as of 18 August 2020 [2]. Most recent studies have largely focused on describing the epidemiological and clinical characteristics and outcomes of the disease in the general population, health care workers and suggested that the most of infections cause a mild form of infection [3]. However, those studies found that older adults and people with medical comorbidities are at higher risk of severe
Submitted : December 26, 2020

Published : February 9, 2021

ISSN: $2593-8339$

DOI: $10.24018 /$ ejmed.2021.3.1.631

\section{A. M. Hoque *}

Kwadabeka Community Health Centre, Durban, South Africa. (e-mail: mhoque75@gmail.com) M. Hoque

South African College of Applied Psychology, Durban, South Africa. M. E. Hoque

Management College of Southern Africa, Durban, South Africa. G. Van Hal

University of Antwerp, Antwerp, Belgium.

*Corresponding Author illness and death, with more men than women [4], [5]. Based on WHO recommendations, mass quarantine measures are implemented in SA and in many countries as the universal disease control measure [6]. In addition to lockdown and home quarantine, SA has also engaged in media campaigns to disseminate information on preventive measures to the general population including pregnant women like many other countries; regular hand washing with water and soap, social distancing is some of the initiatives [7].

The quarantine has restricted people to their homes, to prevent or slow down transmission of the COVID-19 infection in communities and countries irrespective of high and low infection rate [6], [8]. Psychological impact of quarantine alone is known to cause mental distress e g., irritability, loneliness, frustration, anxiety, depression, fear of 
contracting and spreading infection to family members, insomnia, despair, to extreme consequences like suicidal tendency and committing suicide [9]-[13]. Imposed country wide mass quarantine and application of universal infection prevention strategies applied by the nationwide lockdown program in South Africa (SA) may produce psychological impact like mass hysteria, anxiety and distress. Few previous studies have highlighted that mental well-being had negatively been affected in the general and vulnerable populations (like pregnant women) due to COVID-19 pandemic and applied preventive measures [9], [14]-[17]. According to a study in Chinese citizens, it was found that females experienced a higher degree of negative psychological health due to the outbreak [18]. This finding concurred with the previous epidemiological studies that reported women were at a higher risk of developing depression and anxiety that could possibly be due to biological and or socioeconomic factors [19], [20].

Pregnant women are known to be vulnerable to many infectious diseases that can cause adverse effects not only to maternal but also to foetal outcomes [21]. Thus, pregnant women are considered to be a unique and special population as a result of 'immune suppression' caused by pregnancy [21]. Furthermore, the known immunological and physiological changes of pregnancy when infected are found to be related with higher risk of severe illness or mortality in general and also more specifically due to COVID-19 compared with the general population or non-pregnant women [21], [22]. In general, around $10 \%$ of pregnant women are known to suffer from depression and this rate increases to $16 \%$ in developing countries [23]. Mental health problems among this vulnerable group are expected to increase by the mental health repercussion due to COVID-19 pandemic [24]. It has become a public health crisis as it impacted on the social, demographic and economic problems the society and impacted substantially negative psychosocial effect on all including pregnant women. Anxiety of pregnant women alone is a known negative predictor of pregnancy complications such as depression, preeclampsia, nausea, vomiting and preterm labour or miscarriage [25].

WHO has recommended that the countries of high COVID-19 infection to take the necessary actions against the negative impact on psychological health and well-being of the general population [26]. However, to the best of our knowledge, there is very little known about the psychological problems pregnant women are experiencing in SA due to COVID-19. Therefore, the objectives of this study were to assess and estimate the anxiety, depression, and overall psychological problems during the COVID-19 crisis among pregnant women attending a primary health care setting in Durban, South Africa.

\section{MATERIALS AND METHOD}

\section{A. Study Design}

This was a cross-sectional study conducted among pregnant women attending Kwadabeka Community Health Center (KCHC), a primary health care center running maternity services using national guidelines in a peri-urban setting of Durban, South Africa during the early stage of the epidemic [27].

\section{B. Study Settings, Sample Size, Participant Selection, Data Collection and Measurements}

The study settings, sample size and selection as well as data collection strategy is explained elsewhere [28]. Any pregnant woman screened positive for COVID-19 was excluded from the study. A questionnaire was used for data collection. The questionnaire dealt with pregnant women's demographics (age, education, employment and marital status), personal, medical and obstetric risk (parity, gestational age, vulnerable co-morbidity), alcohol habits and household $(\mathrm{HH})$ risk factors (number of people living in a $\mathrm{HH}$, respondent living with one or more children under 5 years and respondent living with one or more elderly of 60 years or over), whether the $\mathrm{HH}$ had adequate funding for daily living before and during the epidemic. Generalized Anxiety Disorder (GAD-7) and Patient Health Questionnaire scales (PHQ-9) were adopted to measure anxiety and depression [29], [30]. Seven-items for GAD-7 and nineitems for PHQ-9 symptom questions were used respectively to measure anxiety and depression problems during the past 2 weeks [31], [32]. Responses to each of the questions had 4 options: "not at all," "several days," "more than half of the days" and" nearly every day," scored as 0, 1, 2, and 3, respectively for all questions to measure anxiety, depression, and overall psychological problems. Any respondent found with either anxiety and or depression problems was then referred to social workers' clinic for intervention at $\mathrm{KCHC}$.

\section{Data Analysis}

Data were captured in Microsoft Excel and exported to SPSS version 22 for analysis. Descriptive statistics were used such as mean with standard deviation (SD) for continuous variables and frequency distribution for categorical variables. The prevalence of anxiety, depression and overall psychological levels were reported. Both anxiety and depression problems were measured using cutoff points of the summary scores 5,10 and 15 to classify or categorize as mild, moderate and severe anxiety and depression respectively as based on other reports [33]. Therefore, the total scores for GAD-7 and PHQ-9 were separately categorized to represent: (1-5) none or minimal, (6-9) mild, (10-14) moderate and (> 15) severe anxiety and depression. However, the cut off points of GAD-7 and PHQ-9 scores $>10$ for anxiety and depression disorders were considered based on previous published studies [34], [35]. The combined GAD-7 and PHQ-9 scores > 20 were used to measure overall psychological problems. The GAD-7 (score $>10=1$ and $<9=0$ ), PHQ-9 (scores $>10=1$ and $<9=0$ ) and overall psychological scores $(>20=1$ and $<19=0$ ) were treated as dichotomous variables for the bivariate and multivariate analysis. Pearson's correlation test was conducted to determine the relationship between anxiety and depression scores. Cross table analysis with Chi-square test was used to identify associated factors for anxiety, depression, and overall psychological problems. Binary logistic regression (backward stepwise) analysis was undertaken to identify the predictors for anxiety, depression, and overall psychological problems. The results were reported as OR (odds ratio) with 95\% Confidence Interval (CI). All tests were two-tailed, with a significance level of $\mathrm{p}<0.05$. 


\section{Ethical Consideration}

Ethical approval was obtained from Health Ethics Review Board (Reference no. 06/2020). Permission from the KCHC management was obtained to undertake the study (reference no. 02/2020). Anonymity and confidentiality of the respondents was maintained at all times. Participation in the study was voluntary. The study obtained informed consent from the participants after explaining the purpose, nature and objectives of the study.

\section{RESULTS}

The study recruited 346 pregnant women with the mean age of $26.7(\mathrm{SD}=6.81)$ years and $14.8 \%$ were teenage pregnancy (age $<20$ years). Majority $(82 \%)$ belonged to ages between 20 to 39 years and $71.4 \%$ was single (Table I). More than half $(52 \%)$ of them were unemployed and having lower level of education $(73 \%$ had matric or below education). The mean gestational age was 23.8 (SD 6.83) weeks and most of them were in their late gestation $(48.8 \%$ and $32.4 \%$ in second and third trimesters). Nearly half (49\%) were nulliparous, meaning having or experiencing first pregnancy. The mean number of people per household was 3.56 (SD 2.3) and majority (52.6\%) HH had between 1-3 people. The respondents living with high-risk population for COVID-19 were $44.4 \%$ (children $<5$ years) and $25.1 \%$ with people with age $>60$ years respectively. Half $(50.29 \%)$ of the respondents had known vulnerable comorbidities for COVID-19. Among these, the highest prevalence was HIV (28\%) followed by known hypertension (11.3\%), chronic asthma (7\%), diabetes (3\%) (not shown in table). However, some respondents $(3 \%)$ had more than one comorbidity. Over half of the respondents $(53 \%)$ reported that they had adequate funding before the COVID-19 epidemic. Adequate funding at the household level went down to $27.7 \%$ during the epidemic. Only $7.5 \%$ of pregnant women reported to consume alcohol before the epidemic and the rate went down to $1.8 \%$ during the epidemic.

\section{A. Prevalence of Anxiety, Depression, and Overall Psychological Disorders}

Majority $(62.6 \%, 60.6 \%$ and $65.7 \%)$ of the respondents had minimal to mild forms of anxiety, depression and overall psychological problems respectively (Fig. 1). However, considering the generalized anxiety and depression disorder among pregnant women (GAD-7 and PHQ scores >10 individually) $35.7 \%$ and $38.2 \%$ were found with anxiety and depressive disorders respectively. Similarly, more than onethird $(34.3 \%)$ of the respondents were found with overall psychological problem.

B. Demographic Variables and Its Association with Anxiety, Depression, and Overall Psychological Disorders

Chi-Square test of association was undertaken to identify the demographic variables significantly associated with anxiety and depression disorders, and overall psychological problems (results not shown).
TABLE I: DEMOGRAPHIC, PERSONAL AND HOUSEHOLD VARIABLES OF THE

\begin{tabular}{|c|c|c|}
\hline Variables & Frequency & Percentage \\
\hline \multicolumn{3}{|l|}{ Age $(n=346)$} \\
\hline$<20$ years/ Teenage & 50 & 14.5 \\
\hline $20-29$ years & 172 & 49.7 \\
\hline 30- 39 years & 111 & 32.1 \\
\hline$>=40$ years & 13 & 3.7 \\
\hline Mean (SD) age & \multicolumn{2}{|c|}{27 years (SD 6.81) } \\
\hline \multicolumn{3}{|l|}{ Parity $(n=346)$} \\
\hline Nil (0) parity & 169 & 48.8 \\
\hline Parity 1 & 88 & 25.4 \\
\hline Parity 2 & 55 & 15.9 \\
\hline Parity 3 & 26 & 7.5 \\
\hline Parity 4 & 8 & 2.3 \\
\hline \multicolumn{3}{|l|}{ Gestational age $(n=346)$} \\
\hline First trimester & 65 & 18.8 \\
\hline Second trimester & 169 & 48.8 \\
\hline Third trimester & 112 & 32.4 \\
\hline \multicolumn{3}{|l|}{ Marital status $(n=346)$} \\
\hline Single & 247 & 71.4 \\
\hline Married & 60 & 17.3 \\
\hline Others(Living together, widow) & 39 & 11.3 \\
\hline \multicolumn{3}{|l|}{ Employment Status $(\mathrm{n}=346)$} \\
\hline Full- time & 87 & 25.2 \\
\hline Part- time & 80 & 23.1 \\
\hline Unemployment & 179 & 51.7 \\
\hline \multicolumn{3}{|l|}{ Education level $(\mathrm{n}=346)$} \\
\hline No education & 14 & 4 \\
\hline 1- 11 years schooling & 129 & 37.3 \\
\hline Grade 12 & 126 & 36.4 \\
\hline Diploma/ degree & 77 & 22.3 \\
\hline \multicolumn{3}{|l|}{ No. of people in the household $(n=346)$} \\
\hline Between 1-3 people & 182 & 52.6 \\
\hline Between 4-6 people & 135 & 39 \\
\hline 7 or more people & 29 & 8.4 \\
\hline Mean number of people per $\mathrm{HH}$ & $3.56(\mathrm{SD}$ & \\
\hline $\begin{array}{l}\text { Respondents living with } \\
\text { children under } 5 \text { years }\end{array}$ & 154 & 44.5 \\
\hline $\begin{array}{l}\text { Respondents living with elders } \\
>60 \text { years }\end{array}$ & 87 & 25.1 \\
\hline $\begin{array}{l}\text { Presence of known vulnerable } \\
\text { co-morbid conditions }(n=346)\end{array}$ & 167 & 48.3 \\
\hline $\begin{array}{l}\text { Adequate household funding } \\
\text { before COVID-19 epidemic } \\
(n=346)\end{array}$ & 149 & 43.1 \\
\hline $\begin{array}{l}\text { Adequate household funding } \\
\text { during COVID-19 epidemic } \\
(\mathrm{n}=346)\end{array}$ & 96 & 27.7 \\
\hline $\begin{array}{l}\text { Drink alcohol usually and } \\
\text { before COVID-19 epidemic }\end{array}$ & 26 & 7.5 \\
\hline $\begin{array}{l}\text { Drink alcohol during COVID- } \\
19 \text { epidemic }\end{array}$ & 6 & 1.8 \\
\hline
\end{tabular}

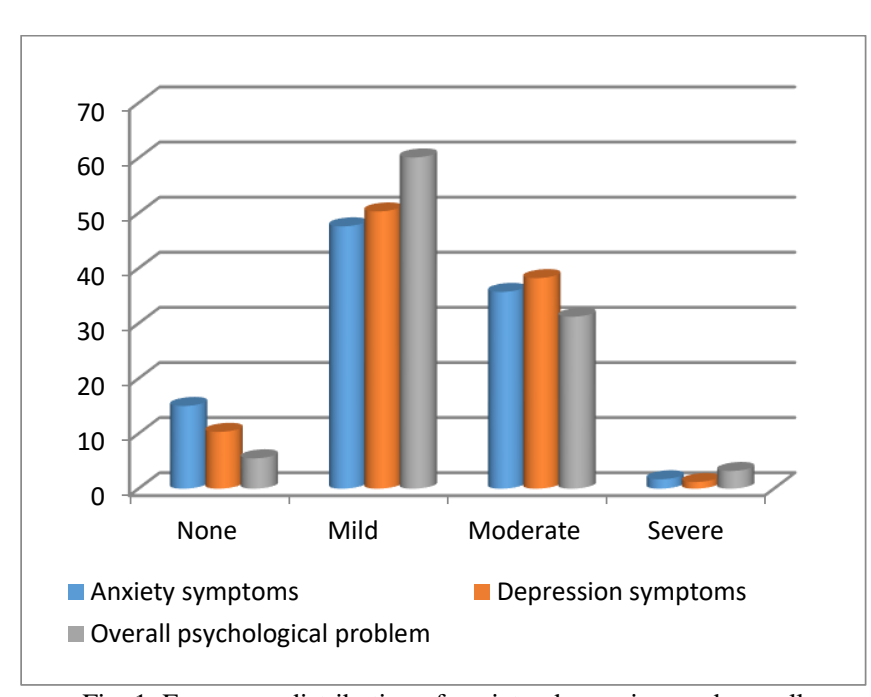

Fig. 1: Frequency distribution of anxiety, depression, and overall psychological disorders in percent among 346 pregnant women.

The following variables found to be significantly associated with anxiety and depression disorders, and overall 
psychological problems were age, education, employment status, parity, gestational age, pregnant women living with people > 60 years, respondents who did not have adequate funding for living, $\mathrm{HH}$ funding before and during the COVID-19 epidemic. Pearson correlation test (Table II) showed that total anxiety scores were significantly but poorly positively correlated with depression scores $(\mathrm{r}=0.168$; $\mathrm{p}<0.05)$

TABLE II: CORRELATIONS TEST RESUlTS OF ANXIETY AND DEPRESSION

\begin{tabular}{llcc}
\multicolumn{3}{c}{ SCORES } \\
\hline \multirow{4}{*}{ Total anxiety } & Pearson Correlation & 1 & Total \\
& Sotal anxiety & Depression \\
\cline { 2 - 3 } & Sig. (2-tailed) & & $.168^{* *}$ \\
Total & $\mathrm{N}$ & 346 & .002 \\
Depression & Pearson Correlation & $.168^{* *}$ & 346 \\
& Sig. (2-tailed) & .002 & 1 \\
& $\mathrm{~N}$ & 346 & 346 \\
\hline
\end{tabular}

\section{Regression Analysis Results}

Binary logistic regression analysis was performed to identify demographic, personal and household risk factors associated with anxiety disorder (GAD-7 score >10), depression (PHQ-9 score >10) and overall psychological problems (scores $>20$ ). The variables that were found to be significantly associated with the dependent variables were initially included in the model. Gestational age between 14 to 26 weeks was $60 \%$ less likely to be related with an anxiety disorder $(\mathrm{OR}=.397, \mathrm{p}<0.05)$ compared to first trimester (gestational age $<13$ weeks) (Table III). Married women were 2.5 times more likely $(\mathrm{OR}=2.54, \mathrm{p}<0.05)$ to have anxiety disorders compared to single women. Similarly, pregnant women living together or being widowed had 2.9 times more risk $(\mathrm{OR}=2.91, \mathrm{p}<0.05))$ to have anxiety problems than single women. Pregnant women who were part time employed were $53 \%$ less likely $(\mathrm{OR}=0.47, \mathrm{p}<0.05)$ to have anxiety problems than those who were unemployed. Similarly, pregnant women having adequate funding for monthly expenses were $62 \%$ less likely $(\mathrm{OR}=0.381, \mathrm{p}<0.05)$ to have an anxiety disorder.

TABLE III: MULTIPLE LOGISTIC REGRESSION ANALYSIS OUTPUT FOR

\begin{tabular}{|c|c|c|c|c|}
\hline \multirow[b]{2}{*}{ Variables } & \multirow[b]{2}{*}{ Sig. } & \multirow[b]{2}{*}{$\operatorname{Exp}(B)$} & \multicolumn{2}{|c|}{$95 \%$ C.I.for $\mathrm{EXP}(\mathrm{B})$} \\
\hline & & & Lower & Upper \\
\hline Gestational age & .019 & & & \\
\hline Gestational age A (1) & .012 & .397 & .194 & .814 \\
\hline Gestational age A (2) & .966 & .989 & .592 & 1.651 \\
\hline Marital status & .098 & & & \\
\hline Marital status (1) & .044 & 2.544 & 1.027 & 6.303 \\
\hline Marital status (2) & .038 & 2.919 & 1.063 & 8.014 \\
\hline Employment status & .063 & & & \\
\hline Employment status (1) & .350 & .768 & .442 & 1.336 \\
\hline Employment status (2) & .020 & .473 & .252 & .887 \\
\hline $\begin{array}{l}\text { Currently have sufficient } \\
\text { funding to cover monthly cost } \\
\text { (1) }\end{array}$ & .000 & .381 & .226 & .643 \\
\hline Constant & .553 & .733 & & \\
\hline
\end{tabular}

Women aged 20 to 29 years were nine times more likely to have a depression disorder $(\mathrm{OR}=9.03, \mathrm{p}=0.016)$ than the teenagers (Table IV). Women aged 30 to 39 years were 6.3 times more likely to have a depression $(\mathrm{OR}=6.3, \mathrm{p}=0.032)$ than the teenagers. Parity one (second time pregnant) women were $91 \%$ less likely to have a depression disorder
(OR=0.094, $\mathrm{p}=0.007)$ than nulliparous women. Parity 2 (women with their third pregnancy) were $86 \%$ less likely $(\mathrm{OR}=.143, \mathrm{p}=0.027)$ to have a depression than those who had no pregnancy before. Part time employment was found with a protective effect $(65 \%$ less likely to have depression ( $\mathrm{OR}=.354, \mathrm{p}=0.002)$ compared to unemployed respondents.

It was found that women aged between 20 to 29 years were 28 times more likely to have overall psychological problems (Table V) than the teenagers $(\mathrm{OR}=27.8, \mathrm{p}<0.01)$. Similarly, older ages (30-39 years) were nine times more likely to have overall psychological problems $(\mathrm{OR}=9.345, \mathrm{p}$ $<0.05)$ than the teenagers. Women with parity 1 were less likely to have overall psychological problems than those being nulliparous $(\mathrm{OR}=0.17, \mathrm{p}<0.05)$. Pregnant women who had adequate funding during the epidemic were less likely to have psychological problems than those who did not have adequate funding $(\mathrm{OR}=0.35, \mathrm{p}<0.05)$.

TABLE IV: MULTIPLE LOGISTIC REGRESSION ANALYSIS OUTPUT FOR

\begin{tabular}{|c|c|c|c|c|}
\hline \multirow{2}{*}{ Variables } & \multirow{2}{*}{ Sig. } & \multirow{2}{*}{$\operatorname{Exp}(B)$} & \multicolumn{2}{|c|}{ 95\%C.I.for EXP(B) } \\
\hline & & & Lower & Upper \\
\hline Category age & .024 & & & \\
\hline Category age (1) & .016 & 9.036 & 1.506 & 54.206 \\
\hline Category age (2) & .032 & 6.309 & 1.175 & 33.879 \\
\hline Category age (3) & .192 & 2.954 & .581 & 15.006 \\
\hline Parity & .001 & & & \\
\hline Parity (1) & .007 & .094 & .017 & .526 \\
\hline Parity (2) & .082 & .219 & .039 & 1.216 \\
\hline Parity (3) & .027 & .143 & .025 & .802 \\
\hline Parity (4) & .507 & .551 & .095 & 3.206 \\
\hline Employment status & .008 & & & \\
\hline Employment status (1) & .259 & .706 & .386 & 1.292 \\
\hline Employment status (2) & .002 & .354 & .183 & .684 \\
\hline Constant & .873 & 1.158 & & \\
\hline
\end{tabular}

TABLE V: MULTIPLE LOGISTIC REGRESSION ANALYSIS OUTPUT FOR OVERALL PSYCHOLOGICAL PROBLEM

\begin{tabular}{|c|c|c|c|c|}
\hline \multicolumn{5}{|c|}{ OVERALL PSYCHOLOGICAL PROBLEM } \\
\hline \multirow{2}{*}{ Variables } & \multirow{2}{*}{ Sig. } & \multirow{2}{*}{$\operatorname{Exp}(B)$} & \multicolumn{2}{|c|}{ 95\% C.I.for EXP(B) } \\
\hline & & & Lower & Upper \\
\hline Category age & .002 & & & \\
\hline Category age (1) & .004 & 27.86 & 2.858 & 271.595 \\
\hline Category age (2) & .045 & 9.34 & 1.050 & 83.214 \\
\hline Category age (3) & .093 & 6.31 & .734 & 54.326 \\
\hline Parity & .003 & & & \\
\hline Parity (1) & .049 & .174 & .031 & .990 \\
\hline Parity (2) & .311 & .410 & .073 & 2.305 \\
\hline Parity (3) & .825 & .821 & .144 & 4.687 \\
\hline Parity (4) & .428 & .469 & .072 & 3.053 \\
\hline $\begin{array}{l}\text { Currently have sufficien } \\
\text { funding to cover my } \\
\text { monthly cost (1) }\end{array}$ & .000 & .355 & .213 & .594 \\
\hline Constant & .400 & .356 & & \\
\hline
\end{tabular}

\section{Discussion}

This study provides an initial insight of psychological problems of pregnant women attending $\mathrm{KCHC}$ at the initial phase of the COVID-19 pandemic in SA. This study is unique because it is the first known study to describe the prevalence of anxiety, depression and overall psychological problems due to the COVID-19 pandemic and psychological or mental health services need for pregnant women attending Primary Health Care (PHC) facilities in SA. The use of GAD-7 and PHQ-9 scales are commonly used to diagnose generalized anxiety and depression disorders in general population. The National Institute for Health and Care Excellence (NICE) recommends using GAD-7 and PHQ-9 scales to measure prenatal anxiety and depression risk in 
pregnant women Therefore, it was found to be suitable for this study.

\section{A. The Demographic Indicators of Pregnant Women with the Index Pregnancy}

Being single (71.4\%), low level of education (only $22 \%$ had post matric education), high unemployment rate (52\%), having inadequate funding before (57\%) and during $72.3 \%$ ) the COVID-19 epidemic in SA is indicative of poor socioeconomic condition. In addition, nearly half of them (44\%) are living with a vulnerable population (children less than 5 years $(44.5 \%)$ and a quarter of them with people over 60 years old and vulnerable medical comorbidities (48.3\%). The presence of these vulnerable people in the $\mathrm{HH}$ and having comorbidities can cause a lot of distress, worry and anxiety to pregnant women.

The reduction of consuming alcohol before the epidemic from $7.5 \%$ to $1.8 \%$ during the epidemic is due to the national lockdown and banning of alcohol and cigarettes sale in SA.

More than one-third of the pregnant women were found with anxiety (37.4\%) and depressive disorders (39.4\%) and overall psychological problems $(34.3 \%)$. These rates are more than double than the psychological problems pregnant women were known to experience during the usual time in developing countries [23], [24]. In general, women are found with a higher degree of psychological problems and it is higher in our study than in the case of China during the COVID-19 epidemic for stress, anxiety, and depression [18]. These findings also concur with previous epidemiological studies among women to be at a higher risk of depression due to their unique biological and socioeconomic factors [19], [20]. Anxiety and depression symptoms and disorders are known to often co-occur among pregnant women, and our analyses also found this. Overall, one third of respondents had psychological problems. Higher psychological impact was associated with younger age similar to other report [37]. Previous reports had already highlighted that the prevalence of anxiety among pregnant women were high and between $15 \%$ and $23 \%$ [25], [38], [39]. Family history (parental) of mental disorders together with low socioeconomic condition had also found associated with increase the risk of anxiety [40]-[42].

\section{B. Factors Influencing Pregnant Women's Psychological Status}

The present study found that demographic variables such as age, levels of education, gestational age, marital status, employment status, adequate financial resources and parity of pregnant women were all factors related to negative psychological status during the COVID-19 pandemic. It was also found that women aged between 20 to 29 years were 9 times and 28 times more likely to have depressive and overall psychological problems than the teenage pregnant women, consistent with another study [43]. In addition, the same study highlighted that a higher prevalence of anxiety and depression are associated with the lower level of education consistent with the results of our study [43]. It is likely because people with a higher education and older ages are more likely to have a self-protection and self-defense psychological mechanism and may gather relevant information and knowledge on the COVID-19 epidemic on their own initiative by different methods. Therefore, older pregnant women may have developed psychological adaptation due to less cognitive bias towards the epidemic diseases.

The results also showed that pregnant women in late gestational age (second trimester) were $65 \%$ less likely to develop anxiety compared to earlier gestation (first trimester) period. It is likely due to morning sickness and other associated symptoms pregnant women usually experience in early gestational period and the development of maternal immune system in early pregnancy and it is known to be very sensitive, to develop anxiety and depression symptoms together with the problems of the COVID-19 pandemic [44].

It is well known that if depression during antenatal period remained untreated, it often results in negative obstetric outcomes and that it is a known risk factor for poor maternal health that may lead to inadequate prenatal care, care during delivery and postnatal depression of mothers [45], [46]. In addition to the possible negative impact on pregnancy outcomes, depression during postnatal period is also linked with disrupted maternal-infant bonding, increased irritability, and decreased activity. Delayed cognitive and language development, lower IQ, and increased prevalence of psychiatric and emotional problems of newborns or children are often found with mothers with psychological problems like depression during and after delivery. Maternal depression during pregnancy is often known to continue or become worse after delivery [47]-[49]. Therefore, there is an urgent need to comprehensively screen all pregnant women for psychological problems e. g., stress, anxiety and depression in existing antenatal care programs to provide proper support to pregnant women in the PHC settings in SA. A detailed mental health crisis program is the demand of time due the COVID-19 pandemic.

This study evaluated the psychological problems of the COVID-19 epidemic among pregnant women in SA at its initial phase. As the epidemic is progressing in SA concerns regarding broader issues of economy, and livelihood together with health are likely to increase day-by-day. This could lead to develop further physical and psychological problems in long run. The findings of the psychological problems estimated in this study could help inform public health managers and policy makers to provide mental health interventions at an individuals and community level of those who are in need. Further studies are recommended to plan prospective longitudinal studies for assessing and determining the long-term psychological problems they could develop and immediate treatment or psychological support to be considered immediately.

\section{STRENGTHS AND LimitATIONS}

The strength of this study is that it is the first known study in a first level health care facility to evaluate and establish the prevalence of psychological or mental health problems due to the COVID-19 epidemic among pregnant mothers in SA. It is a single centre study which limits the generalization of the study findings to the study area. A multi-centre study would have been ideal. We only considered a small convenience sample of respondents in a short period of time. We also consider the cross-sectional study being unable to account for potential changes in anxiety and depression 
levels over a longer period.

\section{CONCLUSION}

Pregnant women are found with higher rates of anxiety, depression, and overall psychological problems during the COVID-19 outbreak. We found that demographic factors/variables such as age, levels of education, gestational age, marital status, employment status, adequate financial resources and parity of pregnant women were all factors related to negative psychological status during the COVID19 pandemic. It is of great importance to provide timely psychological support for pregnant women with mental disorders, to enhance their confidence in being a good mother, and to help them pull through such peculiar time smoothly.

\section{ACKNOWLEDGMENT}

We thank all the participants who voluntarily took part in this study, the two social workers (Mrs Kholowane and Mrs Shabane) who assisted in data collection.

\section{AUTHOR'S CONTRIBUTION}

AMH, MH, MEH, GVH - Conceptualisation, analysis and finalizing of the manuscript.

\section{FUNDING}

There was no funding received to undertake the study.

\section{REFERENCES}

[1] Zhu N, Zhang D, Wang W, et al.: A Novel Coronavirus from Patients with Pneumonia in China, 2019. N Engl J Med. 2020; 382(8): 727-733.

[2] Department of health, Republic of South Africa, National COVID-19 daily report. Available on https://www.nicd.ac.za/contact-us/ . Accessed on 18 August 2020.

[3] Zhou F, Yu T, Du R, Fan G, Liu Y, Liu Z, et al. Clinical course and risk factors for mortality of adult inpatients with COVID-19 in Wuhan, China: a retrospective cohort study. Lancet, 2020; 395(10229): 1054-62.

[4] Wu Z, McGoogan JM. Characteristics of and important lessons from the coronavirus disease 2019 (COVID-19) outbreak in China: summary of a report of 72314 cases from the Chinese Center for Disease Control and Prevention. JAMA, 2020; 323(13):1239-42.

[5] Istituto Superiore di Sanità: Report about the Characteristics of Death Patients Positive to COVID-19 in Italy (Based on Data Updated on 17th March 2020).

[6] Rubin GJ, Wessely S. The psychological effects of quarantining a city. BMJ, 2020; 368 .

[7] World Health Organization: Coronavirus Disease 2019 (COVID-19) Situation Report-78. 2020. Reference Source.

[8] Pulla P. Covid-19: India imposes lockdown for 21 days and cases rise. BMJ, 2020; 368.

[9] Brooks SK, Webster RK, Smith LE, Woodland L et al. The psychological impact of quarantine and how to reduce it: rapid review of the evidence. Lancet, 2020; 395(10227):912-20.

[10] Robertson E, Hershenfield K, Grace SL, Stewart DE. The psychosocial effects of being quarantined following exposure to SARS: a qualitative study of Toronto health care workers. The Canadian Journal of Psychiatry. 2004;49(6):403-7.

[11] Barbisch D, Koenig KL, Shih FY. Is there a case for quarantine? Perspectives from SARS to Ebola. Disaster Medicine and Public Health Preparedness. 2015. 9(5):547-53.

[12] Jeong H, Yim HW, Song YJ, Ki M, Min JA, Cho J, Chae JH. Mental health status of people isolated due to Middle East Respiratory Syndrome. Epidemiol Health. 2016;38.

[13] Liu X, Kakade M, Fuller CJ, Fan B, Fang Y, Kong J, Guan Z, Wu P. Depression after exposure to stressful events: lessons learned from the severe acute respiratory syndrome epidemic. Comprehensive psychiatry. 2012. 53(1):15-23.

[14] Sim K, Chua HC. The psychological impact of SARS: a matter of heart and mind. CMAJ, 2004; 170(5):811-2.

[15] Wu P, Fang Y, Guan Z, Fan B, Kong J, Yao Z, et al. The psychological impact of the SARS epidemic on hospital employees in China: exposure, risk perception, and altruistic acceptance of risk. The Canadian Journal of Psychiatry. 2009;54(5):302-11.

[16] Maunder R, Hunter J, Vincent L, Bennett J, Peladeau N, Leszcz M, Sadavoy J, Verhaeghe LM, Steinberg R, Mazzulli T. The immediate psychological and occupational impact of the 2003 SARS outbreak in a teaching hospital. Cmaj. 2003; 168(10):1245-51.

[17] Hawryluck L, Gold WL, Robinson S, Pogorski S, Galea S, Styra R. SARS control and psychological effects of quarantine, Toronto, Canada. Emerging infectious diseases. 2004. 10(7):1206.

[18] Wang C, Pan R, Wan X, Tan Y, Xu L, Ho CS, et al. Immediate psychological responses and associated factors during the initial stage of the 2019 coronavirus disease (COVID-19) epidemic among the general population in China. Int J Environ Res Public Health 2020; 17 (5):1729-34.

[19] Lim GY, Tam WW, Lu Y, Ho CS, Zhang MW, Ho RC. Prevalence of depression in the community from 30 countries between 1994 and 2014. Scientific reports. 2018; 8(1):1-0.

[20] Albert PR. Why is depression more prevalent in women? J Psychiatry Neurosci JPN 2015; 40:219-21.

[21] Qiao J. What are the risks of COVID-19 infection in pregnant women? The Lancet 2020 ; 395(10226):760-762.

[22] Ortiz EI, Herrera E, De La Torre A. Coronavirus (COVID 19) Infection in Pregnancy. Colombia Médica. 2020. 51(2).

[23] Zeng LN, Chen LG, Yang CM, Zeng LP, Zhang LY, Peng TM. Mental health care for pregnant women in the COVID-19 outbreak is urgently needed. Women and birth: Journal of the Australian College of Midwives. 2020; 1871-5192(20)302109.

[24] Topalidou A, Thomson G, Downe S. COVID-19 and maternal mental health: Are we getting the balance right?. MedRxiv. 2020 Jan 1.

[25] Sasaki T-K, Yoshida A, Kotake K. Attitudes about the 2009 H1N1 influenza pandemic among pregnant Japanese women and the use of the Japanese municipality as a source of information. Southeast Asian J Trop Med Public Health, 2013; 44:388-99.

[26] Yao H, Chen J-H, Xu Y-F. Rethinking online mental health services in China during the COVID-19 epidemic. Asian J Psychiatry. 2020; 50: 102015 .

[27] Department of Health. Guidelines for Maternity Care in South Africa: A Manual for Clinics, Community Health Canters and District Hospitals. 4th ed. Pretoria, South Africa: Department of Health; 2016.

[28] Hoque AM, Bukus S, Hoque M, Hoque ME, Van Hal G. COVID-19 vaccine acceptability among Pregnant Women at a Primary Health Care Facility in Durban, south Africa. European Journal of Medical and Health Sciences ISSN (Online): 2593-8339.

[29] Spitzer RL, Kroenke K, Williams JB, Löwe B. A brief measure for assessing generalized anxiety disorder: the GAD7. Archives of internal medicine, 2006.166(10):1092-7.

[30] Pfizer I. PHQ-9 (Patient Health Questionnaire). Pfizer, New York. 1999. 
[31] He X, Li C, Qian J, et al. . Reliability and validity of a generalized anxiety disorder scale in general hospital outpatients. Shanghai Arch Psychiatry, 2010; 22:200-3.

[32] Que J, Shi L, Deng J, et al. Psychological impact of the COVID-19 pandemic on healthcare workers: a cross-sectional study in China. General Psychiatry, 2020; 33:1002-59.

[33] Spitzer RL, Kroenke K, Williams JBW, et al. A brief measure for assessing generalized anxiety disorder: the GAD-7. Arch Intern Med, 2006;166:1092-7.

[34] Löwe B, Decker $O$, Müller $S$, et al. Validation and standardization of the generalized anxiety disorder screener (GAD-7) in the general population. Med Care, 2008; 46:26674.

[35] Kroenke K, Spitzer RL, Williams JB. The PHQ-9: validity of a brief depression severity measure. J Gen Intern Med, 2001;16:606-13.

[36] The National Collaborating Centre for Mental Health (UK). Antenatal and Postnatal Mental Health: The NICE Guideline on Clinical Management and Service Guidance. Leicester (UK): British Psychological Society; 2007.

[37] Varshney M, Parel JT, Raizada N, Sarin SK (2020) Initial psychological impact of COVID-19 and its correlates in Indian Community: An online (FEEL-COVID) survey. PLoS ONE 15(5): https://doi.org/10.1371/journal.pone.0233874.

[38] Nath S, Ryan EG, Trevillion K, et al. Prevalence and identification of anxiety disorders in pregnancy: the diagnostic accuracy of the two-item Generalised Anxiety Disorder scale (GAD-2). BMJ Open, 2018. 8: 237-66.

[39] Sinesi A, Maxwell M, O'Carroll R, et al. Anxiety scales used in pregnancy: systematic review. BJPsych Open, 2019. 5:(5).

[40] Soto-Balbuena C, Rodríguez MF, Escudero AI. Incidence, prevalence and risk factors related to anxiety symptoms during pregnancy. Psicothema, 2018; 30:257-63.

[41] Craske MG, Stein MB. Anxiety. Lancet Lond Engl, 2016; 388:3048-59.

[42] Bayrampour H, McDonald S, Tough S. Risk factors of transient and persistent anxiety during pregnancy. Midwifery, 2015. 31:582-9.

[43] Zhang Y, Muyiduli X, Wang S, et al. Prevalence and relevant factors of anxiety and depression among pregnant women in a cohort study from south-east China. J Reprod Infant Psychol, 2018. 36(5):519-529.

[44] Jiao J. Under the epidemic situation of COVID-19, should special attention to pregnant women be given? J Med Virol., 2020.

[45] Vizzini L, Popovic M, Zugna D, et al. Maternal anxiety, depression and sleep disorders before and during pregnancy, 1; and preschool ADHD symptoms in the NINFEA birth cohort study. Epidemiol Psychiatr Sci, 2019. 28:521-31.

[46] Nakic' Rados S, Tadinac M, Herman R. Anxiety during pregnancy and postpartum: course, predictors and comorbidity with postpartum depression. Acta Clin Croat 2018;57:39-51.

[47] Verbeek T, Arjadi R, Vendrik JJ, et al. Anxiety and depression during pregnancy in Central America: a cross-sectional study among pregnant women in the developing country Nicaragua. BMC Psychiatry, 2015. 15:292.

[48] Yonkers KA, Gilstad-Hayden K, Forray A, et al. Association of panic disorder, generalized anxiety disorder, and benzodiazepine treatment during pregnancy with risk of adverse birth outcomes. JAMA Psychiatry, 2017. 74:1145-52.

[49] LaRusso EM, Freeman MP. 18 - Antidepressants in Pregnancy. In: Mattison, D.R., editor. Clinical Pharmacology During Pregnancy [Internet]. Academic Press; 2013. 295-305. 